\title{
Self-expandable metal stent placement for malignant esophageal strictures - changes in clinical outcomes over time
}

\author{
Authors \\ Institutions \\ 1 Department of Gastroenterology and Hepatology, \\ Erasmus MC University Medical Center, Rotterdam, The \\ Netherlands \\ 2 Department of Gastroenterology and Hepatology, \\ University Medical Center Utrecht, Utrecht, The \\ Netherlands \\ 3 Department of Gastroenterology and Hepatology, \\ Radboud University Medical Center, Nijmegen, The \\ Netherlands
}

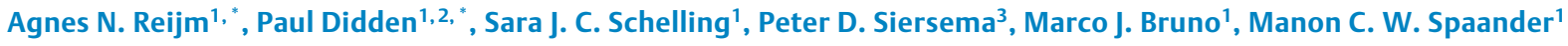

\section{ABSTRACT}

Background Self-expandable metal stents (SEMSs) are effective for improving dysphagia in patients with incurable esophageal cancer but are also associated with recurrent dysphagia and adverse events. In the past decades, new SEMSs have been introduced, but also patients' risk profiles have altered. It is unknown if these changes have affected SEMS outcomes.

Methods This retrospective cohort study was conducted in a tertiary referral center in the Netherlands. Patients submitted 20.11.2017

accepted after revision $\quad$ 17.5.2018

\section{Bibliography}

DOI https://doi.org/10.1055/a-0644-2495

Published online: 10.7.2018 | Endoscopy 2019; 51: 18-29

(c) Georg Thieme Verlag KG Stuttgart · New York ISSN 0013-726X

\section{Corresponding author}

Manon C. W. Spaander, MD PhD, Department of Gastroenterology and Hepatology (room NA 610), Erasmus MC University Medical Centre, 's Gravendijkwal 230, 3015 CE Rotterdam, The Netherlands

Fax: +31-10-7035172

v.spaander@erasmusmc.nl

Table e2, e3, e5

Online content viewable at:

https://doi.org/10.1055/a-0644-2495 who underwent palliative esophageal SEMS placement for malignant dysphagia between 1994 and 2017 were included. The primary outcome was to assess shifts over time with respect to recurrent dysphagia and adverse events after SEMS placement.

Results 997 patients who underwent SEMS placement were included. Recurrent dysphagia occurred in 309 patients (31\%) and remained stable, although with a trend towards an increase over time (hazard ratio [HR] 1.02 per 1year increase; $P=0.05)$. Migration rate significantly increased over time (HR 1.04 per 1-year increase; $P=0.01$ ). SEMS-related complications occurred in 461 patients (46.2\%), with 207 (20.7\%) major and 336 (33.7\%) minor complications. Prior chemoradiotherapy was significantly associated with major complications (HR 1.69; $P<0.001)$. Pain was the most common adverse event and showed a significant increase over time $(P<0.01)$. Factors associated with pain were prior chemoradiotherapy, absence of a fistula, axial and radial forces, and squamous cell carcinoma. Conclusions Despite the introduction of novel esophageal SEMS designs, recurrent dysphagia has not declined over the years. Stent-related complications have increased in recent years, which seems to be mainly associated with more frequent use of chemoradiotherapy prior to SEMS placement.

\section{Introduction}

Annually, approximately 480000 people are diagnosed with esophageal cancer worldwide [1]. More than half of the patients present with inoperable disease at diagnosis because of metastases or poor medical condition [2,3]. Dysphagia is a

\footnotetext{
* Contributed equally to this work.
}

common symptom with a major impact on a patient's quality of life [4]. Brachytherapy [5] and SEMS placement [6] are both effective in diminishing obstructive symptoms. Although brachytherapy has been shown to be superior in achieving longterm relief of dysphagia, SEMS placement results in a more rapid improvement [7]. It is therefore currently accepted that SEMS placement is primarily indicated in patients with an expected short-term survival [8]. 
Since their introduction in the early 1990 s, SEMSs have been used not only for primary esophageal cancer but also for malignant extrinsic compression or fistulas $[9,10]$. They facilitate quick recovery of the passage of food and thereby improve quality of life [11]. Moreover, SEMSs are easy to insert and their placement is successful in nearly all patients $[6,12]$. However, SEMS-related adverse events are not uncommon. Recurrent dysphagia occurs in about one-third of patients and serious complications including hemorrhage, perforation, pneumonia, and fistulas are not infrequently seen $[7,13]$.

In the past decades, various SEMSs have been designed with the intention of minimizing these risks. SEMSs with different materials, shapes, sizes, coverings, and additional antimigration features have been introduced [14-19]. However, it remains uncertain whether these technical developments have had a positive impact on clinical outcome. In addition, the profile of patients who are selected for stent therapy may have changed over the years, mainly because of different management strategies for esophageal cancer.

Therefore, we analyzed all patients who underwent palliative SEMS placement for malignant dysphagia over the past 23 years and aimed to assess shifts over time with respect to recurrent dysphagia and other SEMS-related adverse events.

\section{Methods}

\section{Study population}

All patients who underwent SEMS placement between July 1994 and May 2017 with palliative intent for malignant dysphagia due to an esophageal or cardiac obstruction were included. In addition, patients with a malignant stricture at the anastomosis after esophagectomy with gastric pull-up surgery or with a concomitant fistula were enrolled.

Eligible subjects were identified from the esophageal stent database of the Department of Gastroenterology and Hepatology of the Erasmus University Medical Center (Rotterdam, The Netherlands) which serves a tertiary referral center. Endoscopy registries and clinical studies were also reviewed. Patients who received a self-expandable plastic stent were excluded.

\section{Endoscopic SEMS placement}

Several types of stents have been inserted during the study period. The particular stent chosen depended on local availability, physician's discretion, and inclusion in a study. Stent placement was performed with the patient under conscious sedation. The lesion was inspected and traversed with a standard or pediatric video endoscope. The esophageal location of the tumor was defined using the distance from the incisors to the upper margin of the tumor and subdivided into: proximal, up to $22 \mathrm{~cm}$; mid, from 22 to $28 \mathrm{~cm}$; and distal, below $28 \mathrm{~cm}$.

Stents were inserted over a guidewire and positioned under fluoroscopic monitoring or endoscopic view. The length of the SEMS was determined as the stricture length plus a minimum of $2 \mathrm{~cm}$ at each side. A large-body SEMS was defined as a body diameter $>20 \mathrm{~mm}$, whereas a body diameter up to $20 \mathrm{~mm}$ was considered regular.

\section{Outcomes and data collection}

The primary outcome was to determine the clinical efficacy and safety of esophageal SEMS placement in terms of recurrent dysphagia and other SEMS-related adverse events and to assess shifts in their occurrence over time. Secondary outcome measures were to identify risk factors for recurrent dysphagia and SEMS-related adverse events, technical success rate, improvement of dysphagia, and survival.

The medical records and endoscopy reports of all patients were reviewed and the following data were extracted: age, sex, dysphagia score, prior chemotherapy and/or radiotherapy, length and location of stenosis, histology, date of stent placement, type, length, diameter, and covering (partially or fully covered) of the SEMS, and the use of dilation. Most data were retrospectively reviewed, although data from prospective studies was also included.

Dysphagia was scored according to Ogilvie [20]. Groups of different SEMSs were combined according to their axial and radial force pattern as described previously [21]. Technical information on the SEMS was requested from the manufacturers if information on force pattern was unavailable. Group 1 consisted of SEMSs with a moderate to high radial force and a low axial force; group 2 had a moderate radial and axial force; group 3 had a low radial force and a moderate axial force; and group 4 had a low radial force and a high axial force.

The following outcome parameters were collected: technical success, complications, recurrent dysphagia, and survival. Technical success was defined as adequate deployment and placement of the stent at the intended position. Repositioning was allowed during the same procedure; however, if a second SEMS was indicated for misplacement, this was considered to be a technical failure.

Recurrent dysphagia was defined as stent migration, tissue in- or overgrowth, food occlusion, or other stent-related causes, confirmed by endoscopy. Major complications were defined as life-threatening or severe complications, including perforation, hemorrhage, pneumonia, fever, fistula, or pressure necrosis. Minor complications were defined as non-life-threatening or moderate complications, including retrosternal pain and reflux symptoms. Time to major or minor complications, and to recurrent dysphagia was defined as the number of days from SEMS placement until the first event in time. If a minor and major complication occurred in the same patient, both complications were included.

For the purpose of this study, the study period was divided into six time periods (TPs), with a time span of 3.5 -4 years, according to the date of stent insertion, as follows: period 1 (July 1994 -1997), period $2(1998-2001)$, period 3 (2002-2005), period 4 (2006-2009), period 5 (2010-2013), and period 6 (2014 - May 2017). Data were collected until May 2017.

\section{Statistical analysis}

Occurrence of recurrent dysphagia, major and minor complications, and survival were assessed by the Kaplan-Meier method and compared between the six consecutive TPs using a logrank test. Patients were censored at time of death, after SEMS 
removal, or at end of follow-up. Trends in time on SEMS-related adverse events were evaluated using time as a linear or quadratic variable in a logistic regression model. A univariable Cox regression analysis was performed in order to evaluate the association between multiple covariates, including time of SEMS placement (in years) and occurrence of recurrent dysphagia, subdivided into: migration, tumor and/or tissue growth, and major and minor complications. All variables with a $P<0.20$ in univariable analysis were entered into a multivariable Cox regression proportional hazards model.

Results were expressed in hazard ratios (HRs) with $95 \%$ confidence interval $(\mathrm{Cl})$. Other covariates were: age, sex, prior radiation and/or chemotherapy, presence of a fistula, location of the stenosis, histology, extrinsic compression, and preceding dilation. Length, diameter, covering, and group of SEMSs were included as SEMS-related variables.

The statistical program SPSS version 20.0 (Chicago, Illinois, USA) was used to perform data analysis. Two-sided $P$ values of 0.05 were considered to be the limit of statistical significance.

\section{Results}

\section{Patient characteristics}

A SEMS was inserted in 1003 patients. Six patients were excluded because they were lost to follow-up, leaving 997 patients for the final analysis. Baseline clinical characteristics are shown in - Table 1. All patients had dysphagia $\geq 2$ before SEMS placement, including 106 patients with a concomitant fistula. In the last two TPs, $65 \%$ of patients had been pretreated with chemotherapy and/or radiotherapy, compared with $40 \%$ in the pre- vious periods $(P<0.01)$. In all subjects with prior concomitant chemoradiotherapy, SEMS placement was performed after the treatment had finished. In these patients, SEMS placement was performed for recurrent or residual malignant obstructive disease. The proportion of patients with more distally located disease (i.e. distal esophagus/cardia) seemed to decrease over time, from $64 \%$ in TP1 -3 to $55 \%$ in TP4 $-6(P<0.01)$.

Overall, 11 different types of SEMS were used, and these were not equally divided among the six TPs ( $\triangleright$ Table 1 ). Ultraflex (Boston Scientific, USA) was most frequently used (354 patients; $35.5 \%$ ). The median length was $12 \mathrm{~cm}$ (range $7-17$ ). A stent with a regular body diameter (up to $20 \mathrm{~mm}$ ) was used in $92.2 \%$ of the SEMS placements. In TP5 and TP6, only regular-diameter SEMSs were used. A partially covered SEMS was inserted in $58.3 \%$ of the SEMS placements. In TP4, the proportion of fully covered SEMSs increased to $61.6 \%$. The different SEMS types and their features are shown in $>$ Table $\mathbf{2}$.

\section{Technical success and symptom improvement}

Endoscopic SEMS placement was technically successful in 967 of 997 (97.0\%) patients. Technical failure occurred because of incorrect SEMS placement $(n=22)$ and insufficient SEMS deployment $(n=8)$. The majority of failures resulted in insertion of a second SEMS; however, in two patients the esophageal lumen was found to be too wide to consider a second stent. No difference was seen in technical success between the different TPs $(P=0.53)$. In 389 patients, dysphagia scores were retrieved at baseline and 4 weeks after stent placement. Dysphagia scores improved from a median of grade 3 to grade $0(P<$ 0.001 ) at 4 weeks after SEMS placement.

- Table 1 Baseline characteristics of 997 patients who underwent SEMS placement with palliative intent for the alleviation of malignant dysphagia from July 1994 to May 2017.

\begin{tabular}{|c|c|c|c|c|c|c|c|}
\hline & $\begin{array}{l}\text { Total } \\
(n=997)\end{array}$ & $\begin{array}{l}\text { TP1 } \\
(n=121)\end{array}$ & $\begin{array}{l}\text { TP2 } \\
(n=268)\end{array}$ & $\begin{array}{l}\text { TP3 } \\
(n=150)\end{array}$ & $\begin{array}{l}\text { TP4 } \\
(n=216)\end{array}$ & $\begin{array}{l}\text { TP5 } \\
(n=156)\end{array}$ & $\begin{array}{l}\text { TP6 } \\
(n=86)\end{array}$ \\
\hline Age, mean $\pm S D$, years & $66.6 \pm 11.7$ & $66.0 \pm 14.2$ & $66.6 \pm 12.0$ & $65.9 \pm 11.3$ & $66.3 \pm 11.1$ & $66.9 \pm 11.0$ & $69.1 \pm 10.0$ \\
\hline \multicolumn{8}{|l|}{ Sex, n (\%) } \\
\hline - Male & $731(73.3)$ & $90(74.4)$ & $198(73.9)$ & $103(68.7)$ & $150(69.4)$ & $123(78.8)$ & 67 (77.9) \\
\hline - Female & $266(26.7)$ & $31(25.6)$ & $70(26.1)$ & $47(31.3)$ & $66(30.6)$ & $33(21.2)$ & $19(22.1)$ \\
\hline Fistula, n (\%) & $106(10.6)$ & $9(7.4)$ & $32(11.9)$ & $11(7.3)$ & $24(11.1)$ & $19(12.2)$ & $11(12.8)$ \\
\hline Extrinsic compression, n (\%) & $69(6.9)$ & $9(7.4)$ & $23(8.6)$ & $2(1.3)$ & $17(7.9)$ & $10(6.4)$ & $8(9.3)$ \\
\hline \multicolumn{8}{|c|}{ Dysphagia score prior stent insertion, n (\%) } \\
\hline - Grade 1 & $0(0)$ & $0(0)$ & $0(0)$ & $0(0)$ & $0(0)$ & $0(0)$ & $0(0)$ \\
\hline - Grade 2 & $76(7.6)$ & $4(3.3)$ & $20(7.5)$ & $13(8.7)$ & $10(4.6)$ & $8(5.1)$ & $21(24.4)$ \\
\hline - Grade 3 & $612(61.4)$ & $69(57.0)$ & $145(54.1)$ & $94(62.7)$ & $153(70.8)$ & $123(78.8)$ & $28(32.6)$ \\
\hline - Grade 4 & $261(26.2)$ & $47(38.8)$ & $84(31.3)$ & $39(26.0)$ & $53(24.5)$ & $24(15.4)$ & $14(16.3)$ \\
\hline Stenosis length, mean $\pm \mathrm{SD}, \mathrm{cm}$ & $7.24 \pm 3.31$ & $7.76 \pm 3.50$ & $7.57 \pm 2.84$ & $7.39 \pm 3.34$ & $6.52 \pm 3.28$ & $7.04 \pm 3.93$ & $6.64 \pm 3.09$ \\
\hline \multicolumn{8}{|l|}{ Location of stenosis, n (\%) } \\
\hline - Proximal esophagus & $131(13.1)$ & $8(6.6)$ & $25(9.3)$ & $23(15.3)$ & $29(13.4)$ & $26(16.7)$ & $20(23.3)$ \\
\hline - Mid-esophagus & $163(16.3)$ & $19(15.7)$ & $41(15.3)$ & $21(14.0)$ & $40(18.5)$ & $26(16.7)$ & $16(18.6)$ \\
\hline
\end{tabular}


$>$ Table 1 (Continuation)

\begin{tabular}{|c|c|c|c|c|c|c|c|}
\hline & $\begin{array}{l}\text { Total } \\
(n=997)\end{array}$ & $\begin{array}{l}\text { TP1 } \\
(n=121)\end{array}$ & $\begin{array}{l}\text { TP2 } \\
(n=268)\end{array}$ & $\begin{array}{l}\text { TP3 } \\
(n=150)\end{array}$ & $\begin{array}{l}\text { TP4 } \\
(n=216)\end{array}$ & $\begin{array}{l}\text { TP5 } \\
(n=156)\end{array}$ & $\begin{array}{l}\text { TP6 } \\
(n=86)\end{array}$ \\
\hline - Distal esophagus & $502(50.4)$ & $65(53.7)$ & $143(53.4)$ & $69(46.0)$ & $106(49.1)$ & $77(49.4)$ & $42(48.8)$ \\
\hline - Cardia & $96(9.6)$ & $18(14.9)$ & $31(11.6)$ & $20(13.3)$ & $16(7.4)$ & $8(5.1)$ & $3(3.5)$ \\
\hline - Post-esophagectomy & $105(10.5)$ & $11(9.1)$ & $28(10.4)$ & $17(11.3)$ & $25(11.6)$ & $19(12.2)$ & $5(5.8)$ \\
\hline \multicolumn{8}{|l|}{ Tumor histology, n (\%) } \\
\hline - Squamous carcinoma & $361(36.2)$ & $41(33.9)$ & $101(37.7)$ & $52(34.7)$ & $71(32.9)$ & $56(35.9)$ & $40(46.5)$ \\
\hline - Adenocarcinoma & $565(56.7)$ & $74(61.2)$ & $146(54.5)$ & $95(63.3)$ & $123(56.9)$ & $89(57.1)$ & $38(44.2)$ \\
\hline - Other & $48(4.8)$ & $2(1.7)$ & $9(3.4)$ & $2(1.3)$ & $16(7.4)$ & $11(7.1)$ & $8(9.3)$ \\
\hline - Unknown & $23(2.3)$ & $4(3.3)$ & $12(4.5)$ & $1(0.7)$ & $6(2.8)$ & $0(0)$ & $0(0)$ \\
\hline \multicolumn{8}{|c|}{ Prior chemotherapy and/or radiotherapy, n (\%) } \\
\hline - None & $530(53.2)$ & $74(61.2)$ & $162(60.4)$ & $89(59.3)$ & $121(56.0)$ & $49(31.4)$ & $35(40.7)$ \\
\hline - Chemotherapy & $229(23.0)$ & $26(21.5)$ & $53(19.8)$ & $30(20.0)$ & $42(19.4)$ & $52(33.3)$ & $26(30.2)$ \\
\hline - Radiotherapy & $80(8.0)$ & $7(5.8)$ & $26(9.7)$ & $7(4.7)$ & $21(9.7)$ & $12(7.7)$ & $7(8.1)$ \\
\hline - Chemoradiotherapy & $140(14.0)$ & $11(9.1)$ & $18(6.7)$ & $19(12.7)$ & $32(14.8)$ & $42(26.9)$ & $18(20.9)$ \\
\hline - Unknown & $18(1.8)$ & $3(2.5)$ & $9(3.4)$ & $5(3.3)$ & $0(0)$ & $1(0.6)$ & $0(0)$ \\
\hline \multicolumn{8}{|l|}{ Pre-SEMS dilation, n (\%) } \\
\hline - No & $882(88.5)$ & $102(84.3)$ & $221(82.5)$ & $128(85.3)$ & $196(90.7)$ & $151(96.8)$ & $84(97.7)$ \\
\hline - Yes & $115(11.5)$ & $19(15.7)$ & $47(17.5)$ & $22(14.7)$ & $20(9.3)$ & $5(3.2)$ & $2(2.3)$ \\
\hline \multicolumn{8}{|l|}{ SEMS placed, n (\%) } \\
\hline - Ultraflex & $354(35.5)$ & $8(6.6)$ & $138(51.5)$ & $66(44.0)$ & $70(32.4)$ & $54(34.6)$ & $18(20.9)$ \\
\hline - Niti-s & $93(9.3)$ & $0(0)$ & $0(0)$ & $41(27.3)$ & $41(19.0)$ & $3(1.9)$ & $8(9.3)$ \\
\hline - Gianturco-Z & $126(12.6)$ & $58(47.9)$ & $66(24.6)$ & $2(1.3)$ & $0(0)$ & $0(0)$ & $0(0)$ \\
\hline - Flamingo & $121(12.1)$ & $55(45.5)$ & $60(22.4)$ & $6(4.0)$ & $0(0)$ & $0(0)$ & $0(0)$ \\
\hline - Choo & $27(2.7)$ & $0(0)$ & $4(1.5)$ & $11(7.3)$ & $12(5.6)$ & $0(0)$ & $0(0)$ \\
\hline - FerX-Ella & $24(2.4)$ & $0(0)$ & $0(0)$ & $24(16.0)$ & $0(0)$ & $0(0)$ & $0(0)$ \\
\hline - Alimaxx & $47(4.7)$ & $0(0)$ & $0(0)$ & $0(0)$ & $47(21.8)$ & $0(0)$ & $0(0)$ \\
\hline - SX-Ella & $27(2.7)$ & $0(0)$ & $0(0)$ & $0(0)$ & 27 (12.5) & $0(0)$ & $0(0)$ \\
\hline - Hanaro & $33(3.3)$ & $0(0)$ & $0(0)$ & $0(0)$ & $6(2.8)$ & $18(11.5)$ & $9(10.5)$ \\
\hline - Evolution & $68(6.8)$ & $0(0)$ & $0(0)$ & $0(0)$ & $13(6.0)$ & 42 (26.9) & $13(15.1)$ \\
\hline - WallFlex & $77(7.7)$ & $0(0)$ & $0(0)$ & $0(0)$ & $0(0)$ & $39(25.0)$ & $38(44.2)$ \\
\hline SEMS length, median (range), cm & $12(7-17)$ & $12(10-16)$ & $12(10-15)$ & $12(8-17)$ & $11(7-17)$ & $11(8-17)$ & $12(8-17)$ \\
\hline \multicolumn{8}{|l|}{ SEMS diameter, n (\%) } \\
\hline - Regular & $919(92.2)$ & $114(94.2)$ & $226(84.3)$ & $141(94.0)$ & $196(90.7)$ & $156(100)$ & $86(100)$ \\
\hline - Large & $78(7.8)$ & $7(5.8)$ & $42(15.7)$ & $9(6.0)$ & $20(9.3)$ & $0(0)$ & $0(0)$ \\
\hline \multicolumn{8}{|l|}{ SEMS covering, $\mathrm{n}(\%)$} \\
\hline - Partially covered & $581(58.3)$ & $63(52.1)$ & $198(73.9)$ & $72(48.0)$ & $83(38.4)$ & $115(73.7)$ & $50(58.1)$ \\
\hline - Fully covered & $416(41.7)$ & $58(47.9)$ & $70(26.1)$ & $78(52.0)$ & $133(61.6)$ & $41(26.3)$ & $36(41.9)$ \\
\hline
\end{tabular}

SEMS, self-expandable metal stent; SD, standard deviation; TP, time period. TP1, 1994-1997; TP2, 1998- 2001; TP3, 2002 - 2005; TP4, 2006-2009; TP5, 2010 - 2013; TP6, 2014-2017. 


\section{Recurrent dysphagia}

Recurrence of dysphagia occurred in 309 of 997 patients $(31.0 \%)$ and was related to tumor and/or hyperplastic tissue in- or overgrowth $(n=136)$, migration $(n=114)$, food occlusion $(n=70)$, other stent-related causes $(n=12)$, and non-stentrelated causes $(n=4)$ ( $\nabla$ Fig. $1 \mathbf{a}$ and $\triangleright$ Table $\mathbf{3}$ ). Recurrent dysphagia was diagnosed after a median of 56 days (range 1 -779). The time free of recurrent dysphagia was significantly different between the six TPs $(P=0.008)(\nabla$ Fig. 2a). A quadratic effect of time on the occurrence of recurrent dysphagia $(P=0.03)$ and migration ( $P=0.002)$ was observed, with both showing an initial increase over the years, and a later decline ( $\boldsymbol{F}$ Fig. 3a,b).

Univariable Cox regression analysis demonstrated a trend towards an increase in recurrent dysphagia over time (HR 1.02 per 1 -year increase, $95 \% \mathrm{Cl} 1.00-1.04 ; P=0.05)$. In multivariable analysis, the relative risk of recurrent dysphagia was decreased for fully covered SEMSs (HR 0.77, $95 \% \mathrm{Cl} 0.61-0.98$; $P$ $=0.03)$ and increased for SEMSs with regular body diameter (HR $1.78,95 \% \mathrm{Cl} 1.05-3.00 ; P=0.03)$ ( $\vee$ Table 4$)$. In addition, an association between prior chemotherapy and recurrent dysphagia was found (HR 1.32, $95 \% \mathrm{Cl} 1.01-1.73 ; P=0.04$ ).

Placement of a SEMS at a later point in time was associated with an increased migration risk (HR 1.04 per 1-year increase, $95 \% \mathrm{Cl} 1.01-1.07 ; P=0.01)$. After adjustment, the relative risk of SEMS migration was increased for fully covered SEMSS (HR 1.61, $95 \% \mathrm{Cl} 1.07-2.43 ; P=0.02$ ), regular-diameter SEMSs (HR $4.19,95 \% \mathrm{Cl} 1.02-17.24 ; P=0.047)$, and SEMSs placed in a later TP (HR 1.04 per 1-year increase, 95\%Cl 1.00-1.07; $P=0.04$ ) ( $\triangleright$ Table e5).

With respect to tumor and/or tissue growth, fully covered SEMSs were associated with a lower risk (HR 0.59, $95 \% \mathrm{Cl}$ $0.39-0.89 ; P=0.01)$ ( $\triangleright$ Table e5).

\section{Other adverse events}

Almost half of the patients (461 patients; $46.2 \%$ ) had at least one complication. Major complications occurred in 207 patients $(20.8 \%)$, including hemorrhage $(n=80)$, pneumonia $(n=$ $51)$, fever $(n=49)$, fistula $(n=28)$, perforation $(n=19)$, and pressure necrosis $(\mathbf{n}=19)$ ( $\triangleright$ Fig. $1 \mathbf{b}$; $>$ Table e3). Major complications developed at a median of 16 days after SEMS insertion (range $0-607)$. The time free of major complications differed significantly over the six TPs $(P=0.02)(\triangleright$ Fig. 2 b). Univariable Cox regression analysis did not show an increase of major complications over time (HR 0.99 per 1 -year increase, $95 \% \mathrm{Cl} 0.96$ $1.01 ; P=0.21)$. However, a trend towards a quadratic effect of time on major complications was seen $(P=0.07)$. A decline was seen from 1995 to 2008, followed by an increase until 2017 ( Fig.3c).

Multivariable Cox regression analysis for major complications is shown in $>$ Table 6. Prior chemoradiotherapy was the only independent risk factor for major complications (HR 1.69, $95 \% \mathrm{Cl} 1.14-2.49 ; P<0.001)$. Trends were seen for radiotherapy (HR 1.60, $95 \% \mathrm{Cl} 1.00-2.55 ; P=0.05)$, pre-SEMS dilation (HR 1.44, 95\%Cl 0.98-2.11; $P=0.06$ ), adenocarcinoma (HR $0.75,95 \% \mathrm{Cl} 0.55-1.03 ; P=0.08)$, and younger age (HR 0.99, $95 \% \mathrm{Cl} 0.98-1.00 ; P=0.09)$.
For perforation and hemorrhage, similar trends in time were seen. Reducing rates were noted during the first five TPs, with an increase in TP6. However, the quadratic effect of time on each of these adverse events was not statistically significant ( $\triangleright$ Fig.3d,e). The risk of developing perforation was significantly higher after pre-SEMS dilation (9.6\% vs. $0.9 \%$; $P<$ $0.001)$. Dilation was performed up to a median of $13 \mathrm{~mm}$. Women were also more at risk $(4.1 \%$ vs. $1.1 \%$; $P<0.001)$. A trend towards more frequent hemorrhage was seen in distally located strictures ( $9.4 \%$ vs. $6.0 \%$; $P=0.06)$.

Pneumonia was the second most common major complication, with 19 of the 51 patients who developed pneumonia doing so within 3 days after SEMS placement, suggesting aspiration during or directly after the procedure. Pneumonia occurred more frequently in patients who had received prior chemoradiotherapy (12.1\%) compared with those who had received no previous therapy, chemotherapy only, or radiotherapy only ( $3.4 \%, 5.2 \%$, and $5.0 \%$, respectively; $P=0.001)$. The risk was also increased in patients with a proximally located stricture $(8.0 \%$ vs. $3.2 \% ; P=0.001)$ and those treated with a large-diameter SEMSs ( $10.3 \%$ vs. $4.7 \% ; P=0.03)$.

Minor complications occurred in 336 patients (33.7\%), with the majority being related to retrosternal pain $(n=299)$ ( $\triangleright$ Fig.1c). The median time to occurrence of minor complications was 1 day after stent insertion (range $0-345$ ). The time free of minor complications differed significantly over the six TPs $(P<0.01)$, with a substantial deterioration in the last two TPs ( $>$ Fig. $\mathbf{2 c}$ ). Cox regression analysis demonstrated an increase in minor complications over time ( $>$ Table 6 ). Other significant associations were younger age, squamous cell histology, distal location, prior chemotherapy or radiotherapy, and the absence of a fistula.

With regard to retrosternal pain, univariable logistic regression analysis demonstrated a significant increase over time (OR $1.07,95 \% \mathrm{Cl} 1.05-1.10 ; P<0.01)$. In addition, a quadratic effect of time was found, showing a relatively stable rate until 2005 , followed by a significant increase afterwards $(P=0.03)$ ( $\triangleright$ Fig.3f). Pain was also the most common adverse event. Therefore, an additional binary multivariable logistic regression analysis was conducted, which showed the following factors to be significantly associated with the occurrence of pain: prior chemotherapy and/or radiotherapy, absence of a fistula, and SEMSs with axial and radial forces in group 3 compared with those in group 1.In contrast, adenocarcinoma was independently associated with a lower risk ( $\triangleright$ Table 7).

\section{Survival}

Overall median survival was 92 days (range 1-2963). At the end of follow-up, there were 22 patients (2.2\%) who were still alive. Most patients died as a result of tumor progression $(n=$ 903; $90.6 \%$ ), while 22 patients (2.2\%) died because of a stentrelated complication. No significant difference in survival was detected between the six TPs $(P=0.11)(\triangleright$ Fig. $2 \mathbf{d})$. 


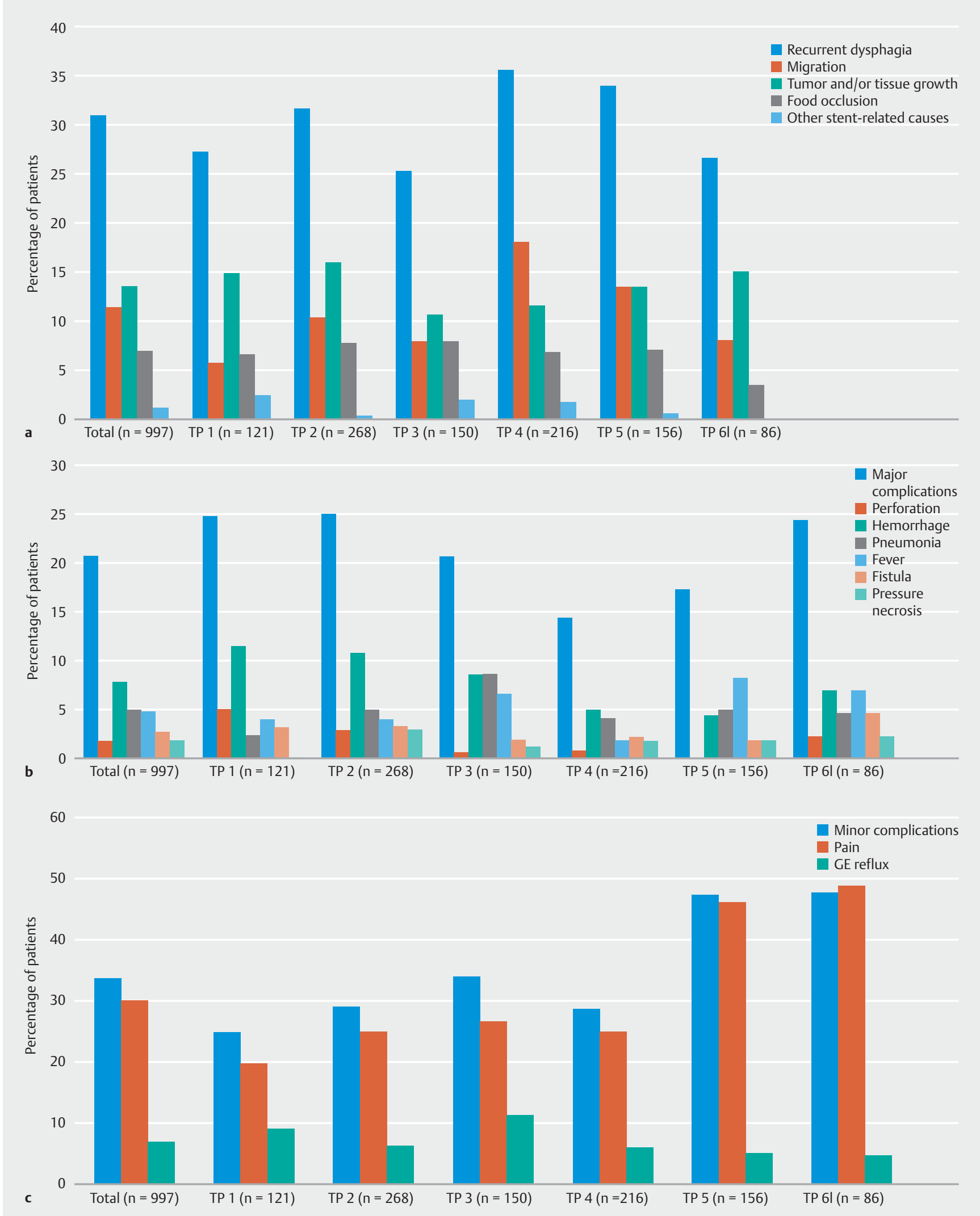

- Fig. 1 Graphs showing changes over the six time periods (TPs) for: a recurrent dysphagia; b major complications; c minor complications. $G E$, gastroesophageal. 

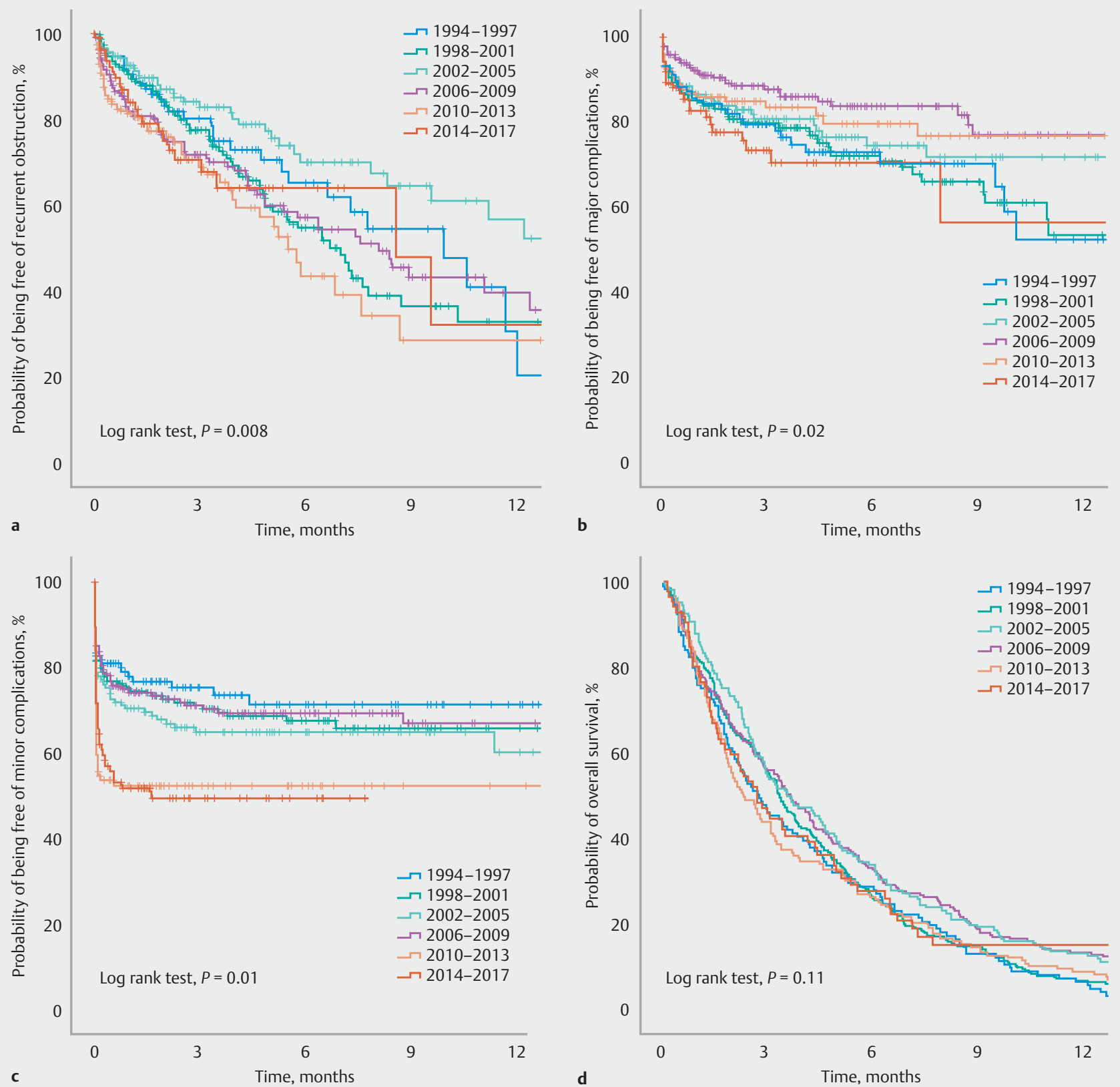

- Fig. 2 Kaplan-Meier analysis of: a survival free of recurrent dysphagia; $\mathbf{b}$ survival free of major complications; $\mathbf{c}$ survival free of minor complications; d overall survival.

\section{Discussion}

This study, which included almost one thousand patients over a period of 23 years, provides a unique insight into time trends in endoscopic SEMS placement for malignant esophageal obstruction pertaining to clinical efficacy and safety.

We showed that SEMS treatment is highly effective in resolving dysphagia. However, recurrent dysphagia is common, occurring in $31.1 \%$ of patients, mostly due to tumor or hyperplastic tissue in- and/or overgrowth, or migration. Despite ongoing technical developments and the introduction of new stent designs, we demonstrated that the overall incidence of recurrent dysphagia has not declined over the years. In fact, a trend towards increasing risk over time was observed, mainly due to a significantly increased risk of SEMS migration. This can be explained by the more frequent use of regular-diameter (maximum $20 \mathrm{~mm}$ ) SEMSs.

In addition, the migration rate was highest in TP4 (20062009), which probably related to the increasing usage of fully covered SEMSs. A fully covered stent design significantly increased the risk of migration, which may be explained by the reduced adhesion and fixation to the esophageal wall [7, 22, 23]. On the other hand, this design is more favorable in preventing 
- Table4 Multivariable Cox regression analysis for recurrent dysphagia.

\begin{tabular}{|c|c|c|}
\hline & $\begin{array}{l}\text { Multivariable } \\
\beta(95 \% \mathrm{CI})\end{array}$ & $P$ value \\
\hline Time (1-year increase) & $1.01(0.99-1.03)$ & 0.28 \\
\hline \multicolumn{3}{|l|}{ Sex } \\
\hline - Male & 1 & \\
\hline - Female & $0.80(0.62-1.05)$ & 0.11 \\
\hline \multicolumn{3}{|l|}{ Histology } \\
\hline - Squamous cell carcinoma & 1 & \\
\hline - Adenocarcinoma & $1.20(0.93-1.54)$ & 0.16 \\
\hline - Other & $1.46(0.81-2.63)$ & 0.20 \\
\hline \multicolumn{3}{|l|}{ Prior treatment } \\
\hline - None & 1 & \\
\hline - Chemotherapy & $1.32(1.01-1.73)$ & 0.04 \\
\hline - Radiotherapy & $0.85(0.53-1.36)$ & 0.49 \\
\hline - Chemoradiotherapy & $0.97(0.66-1.42)$ & 0.87 \\
\hline \multicolumn{3}{|l|}{ SEMS body diameter } \\
\hline - Regular & $1.78(1.05-3.00)$ & 0.03 \\
\hline - Large & 1 & \\
\hline Length of SEMS (10-mm increase) & $0.97(0.91-1.03)$ & 0.29 \\
\hline \multicolumn{3}{|l|}{ Covering SEMS } \\
\hline - Partially covered & 1 & \\
\hline - Fully covered & $0.77(0.61-0.98)$ & 0.03 \\
\hline
\end{tabular}

obstructive tumor and/or hyperplastic in- or overgrowth [24]. Importantly, our data suggests that the protective effect for tumor and/or tissue growth outweighs the migration risk, because a fully covered design reduces the risk of overall recurrent dysphagia.

Whether SEMS force patterns have an impact on recurrent dysphagia is still unclear. Stents with a high radial and low axial force have been proposed to be more appropriate to ensure luminal patency and limit traumatic injury [21]. However, clinical studies to support this hypothesis are lacking. We could not demonstrate a beneficial effect of any one particular force pattern on recurrent dysphagia, migration, or tumor and/or tissue growth.

Not only recurrent dysphagia but also other SEMS-related adverse events have a negative impact in patients with incurable disease. Complications were seen in almost half of the patients, including major complications in $21 \%$. We believe that the following findings regarding this topic deserve further discussion.

First of all, we observed a marked decline in major complications during the first four TPs (1994-2009), which can be ex- plained by a drop in the hemorrhage and perforation rates. The observed decrease in hemorrhage may be related to a shift in stricture location. A gradual increase in the proportion of patients treated for more proximally located disease was observed and the risk of bleeding tended to be lower in these patients compared with those with a distal esophageal obstruction. This association has not been described in previous reports, where only the presence of an esophageal fistula and a concomitant tracheal stent were identified as potential risk factors for major bleeding [25]. However, it is known that the cardia is intensely vascularized, which might contribute to a higher bleeding tendency through stent-induced mechanical injury. Anticoagulants could potentially influence outcome, but information on their use was not available in our cohort.

Perforation is another devastating iatrogenic complication. We noticed that the risk of perforation was significantly higher when dilation had been performed to facilitate SEMS insertion. Pre-SEMS dilation was more commonly done in the earlier days and nowadays has been largely abandoned. Current delivery systems are designed to non-traumatically traverse tight strictures, obviating the need for dilation.

Second, a remarkable increase in the major complication rate was seen during the last two TPs (2010-2017). The increased number of patients treated with chemoradiotherapy prior to SEMS placement is likely responsible. Prior chemoradiotherapy had more than doubled in the last two TPs compared with the first four periods. Several studies have also looked into this association, but conflicting results have been reported [26-30]. Observations from the current study, the largest patient cohort reported to date, provides strong evidence for an increased risk of major complications when patients have been exposed to both chemotherapy and radiotherapy before SEMS placement. Interestingly, a significant association could not be established for either chemotherapy or radiotherapy alone. This suggests a cumulative effect of both treatments. Nevertheless, considering the lack of alternative palliative measures, we believe that SEMSs for recurrent malignant dysphagia after chemoradiotherapy can still be advocated [30]. Obviously, the relatively high risk of major complications should be discussed with patients as part of obtaining proper informed consent.

We found that after chemoradiotherapy patients were more prone to develop pneumonia in particular. Possible mechanisms for increased susceptibility include pulmonary toxicity leading to diminished respiratory tract cleaning, immunosuppressive status, decrease in esophageal wall motility, and the presence of an esophagorespiratory fistula [31-33]. In addition, we found that $37 \%$ of pneumonias occurred within 3 days after SEMS placement. It is likely that, at least in these cases, procedure-related aspiration has triggered a pulmonary infection. This emphasizes the importance of close patient monitoring during endoscopic SEMS placement.

Retrosternal pain after SEMS deployment was the most frequently observed minor complication in our cohort, occurring in $30 \%$ of patients. The rate increased substantially in the last two TPs (2009-2017). Several explanations can be proposed. First, during the last two TPs, a prospective study was conducted in our center, which used a symptom diary to evaluate pain 

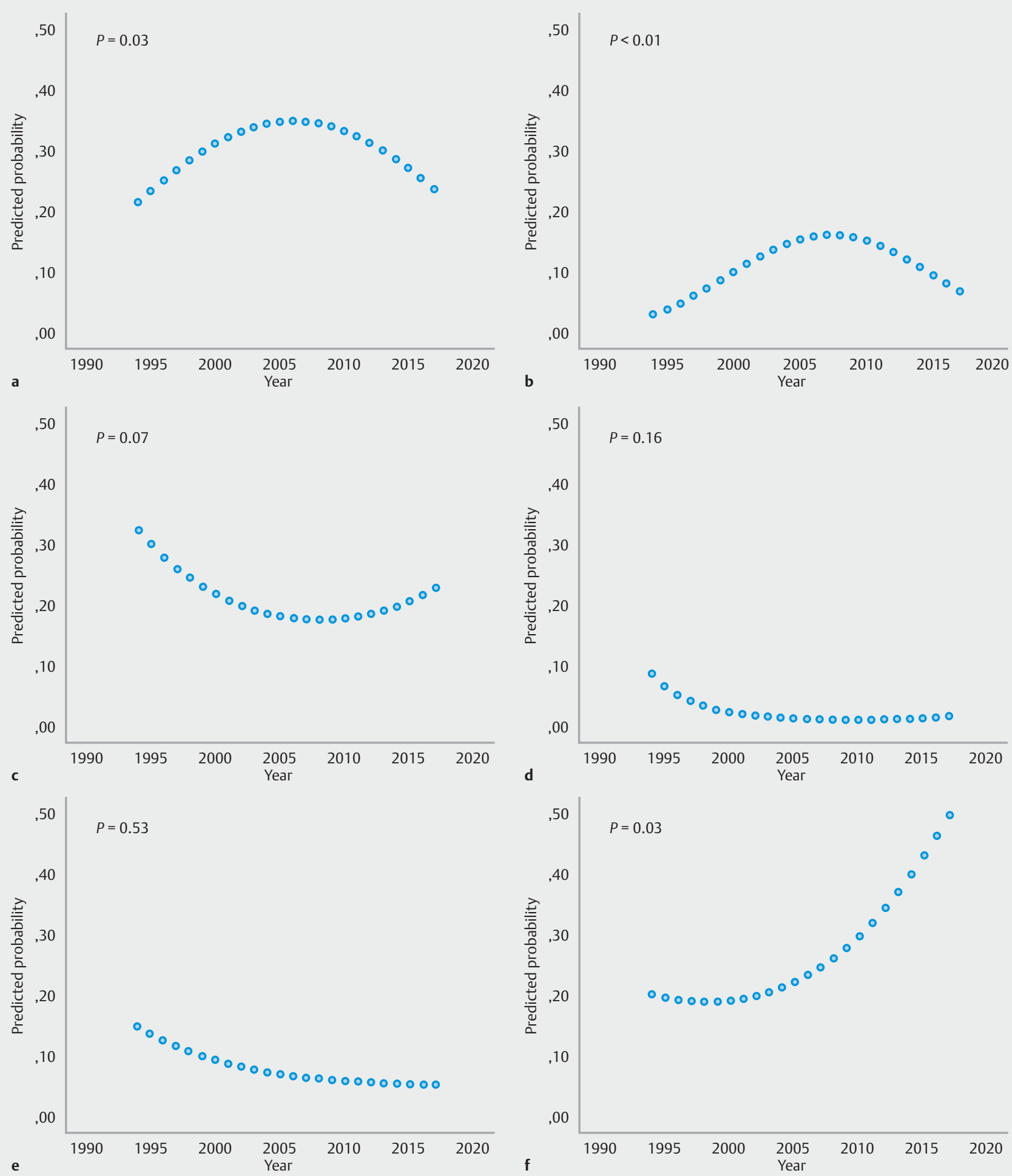

- Fig. 3 Trend analysis looking at quadratic effect of time on: a recurrent dysphagia; b migration; c major complications; $\mathbf{d}$ perforation; e hemorrhage; $f$ pain.

experience after esophageal SEMS placement [34]. This triggered a more precise and trustworthy registration of pain compared with assessments during the earlier years. Second, more patients were pretreated with chemotherapy and/or radiother- apy, and this was marked as an independent risk factor for retrosternal pain. The exact mechanism for enhanced pain experience after pretreatment is unclear. It is conceivable that fibrosis induced by chemoradiotherapy leads to diminished compliance 
- Table 6 Multivariable Cox regression analysis for major and minor complications.

\begin{tabular}{|c|c|c|c|c|}
\hline & \multicolumn{2}{|c|}{ Major complications } & \multicolumn{2}{|c|}{ Minor complications } \\
\hline & $\begin{array}{l}\text { Multivariable } \\
\beta(95 \% \mathrm{Cl})\end{array}$ & $P$ value & $\begin{array}{l}\text { Multivariable } \\
\beta(95 \% \mathrm{Cl})\end{array}$ & $P$ value \\
\hline Time (1-year increase) & & & $1.04(1.01-1.06)$ & $<0.001$ \\
\hline Age (1-year increase) & $0.99(0.98-1.00)$ & 0.09 & $0.99(0.98-1.00)$ & 0.03 \\
\hline \multicolumn{5}{|l|}{ Histology } \\
\hline - Squamous cell carcinoma & 1 & & 1 & \\
\hline - Adenocarcinoma & $0.75(0.55-1.03)$ & 0.08 & $0.72(0.56-0.93)$ & 0.01 \\
\hline - Other & $0.86(0.41-1.78)$ & 0.68 & $0.66(0.35-1.24)$ & 0.20 \\
\hline \multicolumn{5}{|l|}{ Extrinsic compression } \\
\hline - Yes & & & $1.65(0.99-2.73)$ & 0.05 \\
\hline - No & & & 1 & \\
\hline \multicolumn{5}{|l|}{ Location of stenosis } \\
\hline - Proximal / mid/anastomosis & $1.08(0.80-1.47)$ & 0.61 & $0.73(0.58-0.94)$ & 0.01 \\
\hline - Distal / cardia & 1 & & 1 & \\
\hline \multicolumn{5}{|l|}{ Prior treatment } \\
\hline - None & 1 & & 1 & \\
\hline - Chemotherapy & $1.03(0.71-1.50)$ & 0.88 & $1.40(1.06-1.85)$ & 0.02 \\
\hline - Radiotherapy & $1.60(1.00-2.55)$ & 0.05 & $1.61(1.09-2.36)$ & 0.02 \\
\hline - Chemoradiotherapy & $1.69(1.14-2.49)$ & $<0.001$ & $1.34(0.96-1.87)$ & 0.08 \\
\hline \multicolumn{5}{|l|}{ Pre-SEMS dilation } \\
\hline - Yes & $1.44(0.98-2.11)$ & 0.06 & & \\
\hline - No & 1 & & & \\
\hline \multicolumn{5}{|l|}{ Fistula } \\
\hline - No & & & 1 & \\
\hline - Yes & & & $0.44(0.27-0.71)$ & $<0.001$ \\
\hline \multicolumn{5}{|l|}{ SEMS group } \\
\hline - Group 1 & 1 & & & \\
\hline - Group 2 & $0.67(0.32-1.37)$ & 0.27 & $0.93(0.56-1.55)$ & 0.78 \\
\hline - Group 3 & $0.91(0.63-1.30)$ & 0.61 & $1.16(0.88-1.53)$ & 0.30 \\
\hline - Group 4 & $0.92(0.61-1.40)$ & 0.69 & $1.26(0.92-1.72)$ & 0.15 \\
\hline \multicolumn{5}{|l|}{ SEMS body diameter } \\
\hline - Regular & $0.71(0.44-1.14)$ & 0.16 & $1.07(0.66-1.74)$ & 0.79 \\
\hline - Large & 1 & & 1 & \\
\hline \multicolumn{5}{|l|}{ SEMS covering } \\
\hline - Partially covered & 1 & & & \\
\hline - Fully covered & $0.89(0.65-1.21)$ & 0.45 & & \\
\hline
\end{tabular}


- Table 7 Multivariable binary logistic regression analysis for retrosternal pain.

\begin{tabular}{|l|l|l|}
\hline & $\begin{array}{l}\text { Multivariable } \\
\boldsymbol{\beta}(95 \% \mathrm{Cl})\end{array}$ & $\boldsymbol{P}$ value \\
\hline Age (1-year increase) & $0.99(0.98-1.00)$ & 0.07 \\
\hline Histology & & \\
\hline - Squamous cell carcinoma & 1 & \\
\hline - Adenocarcinoma & $0.66(0.48-0.89)$ & $<0.001$ \\
\hline - Other & $0.66(0.29-1.52)$ & 0.34 \\
\hline Extrinsic compression & & \\
\hline - Yes & $1.69(0.86-3.33)$ & 0.13 \\
\hline - No & 1 & \\
\hline Prior treatment & & \\
\hline - None & 1 & \\
\hline - Chemotherapy & $1.77(1.23-2.54)$ & $<0.01$ \\
\hline - Radiotherapy & $2.26(1.36-3.75)$ & $<0.01$ \\
\hline - Chemoradiotherapy & $1.83(1.20-2.77)$ & $<0.001$ \\
\hline Fistula & & \\
\hline - No & $1.21(0.64-2.28)$ & 0.56 \\
\hline - Yes & $2.90(1.63-5.16)$ & $<0.01$ \\
\hline SEMS group & 1 & \\
\hline - Group 1 & & \\
\hline - Group 2 & $1.75(1.25-2.44)$ & $<0.001$ \\
\hline - Group 3 & & \\
\hline - Group 4 & & \\
\hline
\end{tabular}

of the esophageal wall with relative overstretching and higher pressures after SEMS expansion compared with patients who were not treated with chemoradiotherapy. In line with this hypothesis, we found a decreased rate of pain where a fistula was present.

Surprisingly, an association between SEMSs with low radial force and moderate axial force (group 3 ) and pain was observed. This group includes the partially covered WallFlex stent, for which a relatively high occurrence of pain has been described previously [17]. A rational explanation for this finding is lacking.

Several limitations of our study should be acknowledged. Our results are mainly based on retrospectively collected data. The occurrence of adverse events could therefore have been underestimated. Furthermore, data on a few potentially relevant variables were lacking. For example, it would have been interesting to assess whether patient condition or the stage of disease have any influence on clinical outcome and adverse events. Previous studies, albeit smaller in size, have denied such a relationship $[26,28]$. Finally, we have used time as a sep- arate variable within a regression analysis to explore trends over a 23-year period. This prohibits the appraisal of fluctuations in the smaller TPs.

In conclusion, our study demonstrates that improving the clinical outcome of stent therapy for malignant esophageal disease is challenging. Although novel stent designs have been introduced over the years, recurrent dysphagia remains a major issue, occurring in approximately one-third of patients. Moreover, changes in management strategies, with more patients being pretreated with chemoradiotherapy, are associated with an increase in major complications, mainly pneumonia, but also the development of retrosternal pain.

\section{Competing interests}

Prof. Bruno has received personal fees as lecturer and consultant. Reports having received institutional financial support for industry and investigator initiated studies from Boston Scientific, Cook Medical, Pentax Medical and 3M. Prof. Siersema has received research support from Ella-CS, Boston Scientific USA and Cook Medical Ireland. Dr. Spaander has received institutional financial support for investigator initiated studies from Boston Scientific. The remaining authors have no competing interests to report.

References

[1] Ferlay J, Shin HR, Bray F et al. Estimates of worldwide burden of cancer in 2008: GLOBOCAN 2008. Int J Cancer 2010; 127: 2893-2917

[2] Lightdale C]. Esophageal cancer. American College of Gastroenterology. Am J Gastroenterol 1999; 94: 20 - 29

[3] Enzinger PC, Mayer RJ. Esophageal cancer. NEJM 2003; 349: 2241 2252

[4] Sagar PM, Gauperaa T, Sue-Ling H et al. An audit of the treatment of cancer of the oesophagus. Gut 1994; 35: 941 - 945

[5] Homs MY, Eijkenboom WM, Coen VL et al. High dose rate brachytherapy for the palliation of malignant dysphagia. Radiother Oncol 2003; 66: $327-332$

[6] Sharma P, Kozarek R. Practice Parameters Committee of American College of Gastroenterology.. Role of esophageal stents in benign and malignant diseases. Am J Gastroenterol 2010; 105: 258 - 273; quiz 274

[7] Homs MY, Steyerberg EW, Eijkenboom WM et al. Single-dose brachytherapy versus metal stent placement for the palliation of dysphagia from oesophageal cancer: multicentre randomised trial. Lancet 2004; 364: $1497-1504$

[8] Spaander MC, Baron TH, Siersema PD et al. Esophageal stenting for benign and malignant disease: European Society of Gastrointestinal Endoscopy (ESGE) Clinical Guideline. Endoscopy 2016; 48: 939-948

[9] Shin JH, Song HY, Ko GY et al. Esophagorespiratory fistula: long-term results of palliative treatment with covered expandable metallic stents in 61 patients. Radiology 2004; 232: 252-259

[10] Van Heel NC, Haringsma J, Spaander MC et al. Esophageal stents for the palliation of malignant dysphagia and fistula recurrence after esophagectomy. Gastrointest Endosc 2010; 72: 249- 254

[11] Diamantis G, Scarpa M, Bocus P et al. Quality of life in patients with esophageal stenting for the palliation of malignant dysphagia. World J Gastroenterol 2011; 17: 144-150

[12] Didden P, Spaander MC, Bruno MJ et al. Esophageal stents in malignant and benign disorders. Curr Gastroenterol Rep 2013; 15: 319 
[13] Conio M, Repici A, Battaglia G et al. A randomized prospective comparison of self-expandable plastic stents and partially covered selfexpandable metal stents in the palliation of malignant esophageal dysphagia. Am J Gastroenterol 2007; 102: 2667-2677

[14] Uitdehaag MJ, Siersema PD, Spaander MC et al. A new fully covered stent with antimigration properties for the palliation of malignant dysphagia: a prospective cohort study. Gastrointest Endosc 2010; 71: $600-605$

[15] van Boeckel PG, Repici A, Vleggaar FP et al. A new metal stent with a controlled-release system for palliation of malignant dysphagia: a prospective, multicenter study. Gastrointest Endosc 2010; 71: 455 460

[16] Siersema PD, Hop WC, van Blankenstein M et al. A comparison of 3 types of covered metal stents for the palliation of patients with dysphagia caused by esophagogastric carcinoma: a prospective, randomized study. Gastrointest Endosc 2001; 54: 145-153

[17] van Boeckel PG, Siersema PD, Sturgess R et al. A new partially covered metal stent for palliation of malignant dysphagia: a prospective follow-up study. Gastrointest Endosc 2010; 72: 1269-1273

[18] Verschuur EM, Repici A, Kuipers EJ et al. New design esophageal stents for the palliation of dysphagia from esophageal or gastric cardia cancer: a randomized trial. Am J Gastroenterol 2008; 103: 304 312

[19] Uitdehaag M], van Hooft JE, Verschuur EM et al. A fully-covered stent (Alimaxx-E) for the palliation of malignant dysphagia: a prospective follow-up study. Gastrointest Endosc 2009; 70: 1082- 1089

[20] Adam A, Ellul J, Watkinson AF et al. Palliation of inoperable esophageal carcinoma: a prospective randomized trial of laser therapy and stent placement. Radiology 1997; 202: $344-348$

[21] Hirdes MM, Vleggaar FP, de Beule M et al. In vitro evaluation of the radial and axial force of self-expanding esophageal stents. Endoscopy 2013; 45: $997-1005$

[22] Verschuur EM, Steyerberg EW, Kuipers EJ et al. Effect of stent size on complications and recurrent dysphagia in patients with esophageal or gastric cardia cancer. Gastrointest Endosc 2007; 65: 592 - 601

[23] Na HK, Song HY, Kim JH et al. How to design the optimal self-expandable oesophageal metallic stents: 22 years of experience in 645 patients with malignant strictures. Eur Radiol 2013; 23: 786-796
[24] Seven G, Irani S, Ross AS et al. Partially versus fully covered self-expanding metal stents for benign and malignant esophageal conditions: a single center experience. Surg Endosc 2013; 27: 2185-2192

[25] Shan M, Lu Z, Guo Q et al. Self-expanding metal stents for palliative treatment of esophageal carcinoma: risk factors for fatal massive bleeding. J Clin Gastroenterol 2012; 46: 758 - 763

[26] Fuccio L, Scagliarini M, Frazzoni L et al. Development of a prediction model of adverse events after stent placement for esophageal cancer. Gastrointest Endosc 2016; 83: 746 - 752

[27] Kinsman KJ, DeGregorio BT, Katon RM et al. Prior radiation and chemotherapy increase the risk of life-threatening complications after insertion of metallic stents for esophagogastric malignancy. Gastrointest Endosc 1996; 43: 196-203

[28] Lecleire S, Di Fiore F, Ben-Soussan E et al. Prior chemoradiotherapy is associated with a higher life-threatening complication rate after palliative insertion of metal stents in patients with oesophageal cancer. Aliment Pharmacol Ther 2006; 23: 1693 - 1702

[29] Homs MY, Hansen BE, van Blankenstein M et al. Prior radiation and/or chemotherapy has no effect on the outcome of metal stent placement for oesophagogastric carcinoma. Eur J Gastroenterol Hepatol 2004; 16: $163-170$

[30] Didden P, Spaander MC, Kuipers EJ et al. Safety of stent placement in recurrent or persistent esophageal cancer after definitive chemoradiotherapy: a case series. Gastrointest Endosc 2012; 76: 426-430

[31] Dimopoulou I, Galani H, Dafni U et al. A prospective study of pulmonary function in patients treated with paclitaxel and carboplatin. Cancer 2002; 94: $452-458$

[32] Gergel T], Leichman L, Nava HR et al. Effect of concurrent radiation therapy and chemotherapy on pulmonary function in patients with esophageal cancer: dose-volume histogram analysis. Cancer J 2002; 8: $451-460$

[33] Bick BL, Song LM, Buttar NS et al. Stent-associated esophagorespiratory fistulas: incidence and risk factors. Gastrointest Endosc 2013; 77 : $181-189$

[34] Reijm AN, Didden P, Bruno MJ et al. Early pain detection and management after esophageal metal stent placement in incurable cancer patients: A prospective observational cohort study. Endosc Int Open 2016; 4: E890-E894 